IZA DP No. 10316

Risk Attitude and Nonmarital Birth

Uwe Jirjahn

Cornelia Struewing

October 2016 


\title{
Risk Attitude and Nonmarital Birth
}

\author{
Uwe Jirjahn \\ University of Trier \\ and IZA
}

Cornelia Struewing

University of Trier

\section{Discussion Paper No. 10316 \\ October 2016}

\author{
IZA \\ P.O. Box 7240 \\ 53072 Bonn \\ Germany \\ Phone: +49-228-3894-0 \\ Fax: +49-228-3894-180 \\ E-mail: iza@iza.org
}

Any opinions expressed here are those of the author(s) and not those of IZA. Research published in this series may include views on policy, but the institute itself takes no institutional policy positions. The IZA research network is committed to the IZA Guiding Principles of Research Integrity.

The Institute for the Study of Labor (IZA) in Bonn is a local and virtual international research center and a place of communication between science, politics and business. IZA is an independent nonprofit organization supported by Deutsche Post Foundation. The center is associated with the University of Bonn and offers a stimulating research environment through its international network, workshops and conferences, data service, project support, research visits and doctoral program. IZA engages in (i) original and internationally competitive research in all fields of labor economics, (ii) development of policy concepts, and (iii) dissemination of research results and concepts to the interested public.

IZA Discussion Papers often represent preliminary work and are circulated to encourage discussion. Citation of such a paper should account for its provisional character. A revised version may be available directly from the author. 
IZA Discussion Paper No. 10316

October 2016

\section{ABSTRACT}

\section{Risk Attitude and Nonmarital Birth}

Using data of adult women from the German Socio-Economic Panel (SOEP), we find that risk tolerance is associated with a higher probability of an out-of-partnership birth. In contrast, we find no association between risk tolerance and the probability of a cohabiting birth.

JEL Classification: D10, J12, J13

Keywords: risk attitude, out-of-partnership birth, cohabiting birth

Corresponding author:

Uwe Jirjahn

University of Trier

Universitätsring 15

54286 Trier

Germany

E-mail: jirjahn@uni-trier.de 


\section{Introduction}

Since the emergence of the economics of the family, economists have been increasingly interested in the determinants of nonmarital birth (e.g., Akerlof et al. 1996, Ekert-Jaffe and Grossbard 2008, Lundberg and Plotnick 1995, Lundberg et al. 2016, Willis 1999, Wolfe et al. 2001). Economic studies have examined factors such as welfare benefits, income, educational achievement, labor market conditions, religiosity, race, and price and effectiveness of birth control. The role of risk attitudes has been largely neglected. ${ }^{1}$ This study examines the influence of risk attitudes on out-of-partnership births and cohabiting births.

We hypothesize that risk tolerance should be particularly associated with a higher probability of out-of-partnership birth. On the one hand, risk tolerance can involve a higher willingness to take the risk of an unwanted pregnancy. Even if a single woman has no wish to have children, a high degree of risk tolerance may induce her to contracept less effectively when engaging in casual sex. On the one hand, risk tolerance can increase a single woman's propensity for a planned pregnancy. If the woman has a wish for a child and does not find a suitable partner, a high degree of risk tolerance may increase her willingness to take the risks associated with single motherhood. These risks involve financial insecurity, future disadvantages in the marriage market, and potentially adverse consequences for the child's health status and school achievement.

By contrast, the relationship between risk attitude and the probability of cohabiting birth is less clear from a theoretical viewpoint. To the extent cohabitation is an unstable form of union, women with a higher degree of risk tolerance should be more likely to give birth to a child during cohabitation. However, cohabitation is often a 
precursor of marriage. A child can even stimulate the transition from cohabitation to marriage. Thus, there may be no or possibly even a negative association between risk tolerance and cohabiting birth.

\section{Data and Variables}

Our empirical analysis uses the SOEP to examine the influence of risk attitude on nonmarital birth. The SOEP is a representative longitudinal survey of private households. It is administered by the German Economic Institute (DIW). Infratest Sozialforschung, a professional survey and opinion institute, conducts the face-to-face interviews. A nucleus of socio-economic and demographic questions is asked annually. Different 'special' topics are sampled in specific waves.

Our empirical analysis focuses on women aged $18-42 .^{2}$ The analysis is based on dummy dependent variables for an out-of-partnership birth and a cohabiting birth. The respective dummy equals one if a woman gives birth to a child in the actual year and equals zero otherwise. For the analysis of out-of-partnership births, we focus on women who are singles in the previous and in the actual year. For the examination of cohabiting births, we consider women who are in a cohabiting relationship in the previous and in the actual year. Taking into account the availability of all variables used for the analysis, the regressions are based on an unbalanced panel for the years 2007, 2009, 2010, 2011, 2012 and 2013.

The explanatory variables are measured one year prior to the actual year. Our key explanatory variable is a unique measure of risk attitude. The underlying question is: "How do you see yourself: Are you generally a person who is fully prepared to take risks 
or do you try to avoid taking risks?” Interviewees respond to the question on an elevenpoint Likert scale ranging from 0 "not at all willing to take risks" to 10 "very willing to take risks”. This measure has been validated by Dohmen et al. (2011) who demonstrate that it is highly correlated with actual risk taking in lottery experiments.

We control for age and its square, education, health, religiosity, economic worries, labor market status, actual working hours, income, and the number of children already living in the woman's household. Furthermore, we include five year dummies, three broad region dummies, and variables for residence in an urban area, child care availability, and male unemployment rate at the federal-state level.

In the estimates on the determinants of cohabiting birth, we additionally account for the partner's age, education, labor market status, and income. We also account for differences in age, education, and income between the partners. As the partner variables have a larger number of missing values, both estimates with and without these variables are provided.

\section{Empirical Analysis}

Our estimations are based on random effects (RE) and correlated random effects (CRE) probit models. The RE probit accounts for a random error component that is associated with each individual but invariant over time. The CRE probit is a parametric fixed effects approach that additionally includes the individual-specific means of the time-varying explanatory variables (Mundlak 1978). As a check of robustness, we also apply the firth logit approach which is a penalized likelihood method taking into account low prevalence of the outcome (Firth 1993). 
Table 1 provides the estimates on risk attitude and out-of-partnership birth. The RE probit, the CRE probit and the firth logit yield qualitatively the same result. A greater risk tolerance is significantly associated with a higher probability of out-of-partnership birth. ${ }^{3}$ Comparing the CRE model with the RE model, it can be seen that the estimated coefficient on risk tolerance and the resulting marginal effect double when fixed effects are taken into account.

For a quantitative assessment of the results, let us consider a two point increase in risk tolerance. This is roughly an increase by one standard deviation. Considering the CRE model, the one standard deviation increase in risk tolerance results in a 0.4 percentage point higher probability of out-of-partnership birth. Taking into account that the mean of the dependent variable is equal to 1 percent, this is an increase in the probability of out-of-partnership birth by 40 percent.

Table 2 shows the estimations on risk attitude and cohabiting birth. The variable for risk attitude does not emerge with a significant coefficient in any of these estimations. ${ }^{4}$ Thus, while our analysis provides evidence of a strong positive association between risk tolerance and out-of-partnership birth, it shows no evidence of a link between risk tolerance and cohabiting birth.

\section{Conclusions}

This study demonstrates that it is important to distinguish between single women and cohabiting women when analyzing the determinants of nonmarital birth. Using data of adults from the SOEP, it finds that single women with a higher degree of risk tolerance are more likely to give birth to a child. This conforms to the notion that out-of- 
partnership birth reflects underlying risk taking behavior, i.e. engaging in casual sex without effective contraception and taking the risks associated with single motherhood. In contrast, our study finds no evidence that the risk attitudes of cohabiting women have an influence on their decision to give birth to a child. This may indicate that cohabitation is perceived as relatively stable, specifically when a child is borne to the cohabiting parents. The birth of a child may even stimulate a subsequent transition from cohabitation to marriage.

We recognize the need for further research within this theme. In particular, it would be interesting to examine if risk tolerance also has an influence on subsequent outcomes of an out-of-partnership birth for both the mother and her child. 
Table 1: Determinants of out-of-partnership birth

\begin{tabular}{|l|c|l|l|l|}
\hline & Mean, SD & RE Probit & CRE Probit & Firth Logit \\
\hline Out-of-partnership birth & $0.01,0.10$ & & & \\
\hline Risk tolerance & $4.86,2.18$ & $0.050[0.001]$ & $0.102[0.002]$ & 0.133 \\
& & $(2.02)^{*}$ & $(2.04)^{*}$ & $(1.98)^{*}$ \\
\hline Pseudo R ${ }^{2}$ & & 0.090 & 0.280 & 0.124 \\
\hline
\end{tabular}

Number of observations $=5,609$. Number of women $=2,141$. Results on the control variables are suppressed to save space. Marginal effects are in square brackets and z-statistics are in parentheses. * Statistically significant at the $5 \%$ level. 
Table 2: Determinants of cohabiting birth

\begin{tabular}{|l|c|c|c|c|}
\hline & Mean, SD & RE Probit & CRE Probit & Firth Logit \\
\hline & \multicolumn{3}{|c|}{ Without partner controls } \\
\hline Cohabiting birth & $0.05,0.21$ & & \\
\hline Risk tolerance & $4.53,2.10$ & $\begin{array}{l}-0.018[-0.002] \\
(0.83)\end{array}$ & $\begin{array}{l}-0.063[-0.005] \\
(1.48)\end{array}$ & -0.042 \\
& & 0.063 & $0.94)$ \\
\hline Pseudo R & \multicolumn{4}{|c|}{ With partner controls } \\
\hline & \multicolumn{4}{|c|}{0.072} \\
\hline Cohabiting birth & $0.05,0.22$ & \multicolumn{3}{|c|}{} \\
\hline Risk tolerance & $4.48,2.08$ & $0.002[0.0002]$ & $-0.019[-0.001]$ & 0.005 \\
& & $(0.09)$ & $(0.35)$ & $(0.09)$ \\
\hline Pseudo R ${ }^{2}$ & & 0.083 & 0.336 & 0.002 \\
\hline
\end{tabular}

Without partner controls: Number of observations $=2,703$. Number of women $=1,200$. With partner controls: Number of observations $=1,727$. Number of women $=762$. Results on the control variables are suppressed to save space. Marginal effects are in square brackets and zstatistics are in parentheses. 


\section{References}

Akerlof, G.A., J.L. Yellen and M.L. Katz. 1996. "An Analysis of Out-of-Wedlock Childbearing in the United States,” Quarterly Journal of Economics CXI: 277-317.

Dohmen, T., A. Falk, D. Huffman, U. Sunde, J. Schupp and G.G. Wagner. 2011. "Individual Risk Attitudes: Measurement, Determinants and Behavioral Consequences,” Journal of the European Economic Association 9: 522-550.

Ekert-Jaffe, O. and S. Grossbard. 2008. "Does Community Property Discourage Unpartnered Births?” European Journal of Political Economy 24: 25-40.

Firth, D. 1993. "Bias Reduction of Maximum Likelihood Estimates,” Biometrica 80: 2738.

Lundberg, S. and R.D. Plotnick. 1995. “Adolescent Premarital Childbearing: Do Economic Incentives Matter?” Journal of Labor Economics 13: 177-200.

Lundberg, S., R.A. Pollak and J. Stearns. 2016. "Family Inequality: Diverging Patterns in Marriage, Cohabitation, and Childbearing,” Journal of Economic Perspectives 30: 79-102.

Mundlak, Y. 1978. "On the Pooling of Time Series and Cross Section Data," Econometrica 46: 69-85.

Schmidt, L. 2008. "Risk Preferences and the Timing of Marriage and Childbearing," Demography 45: 439-460.

Willis, R.J. 1999. “A Theory of Out-of-Wedlock Childbearing,” Journal of Political Economy 107: S33-S64.

Wolfe, B., K. Wilson and R. Haveman. 2001. “The Role of Economic Incentives in Teenage Nonmarital Childbearing Choices,” Journal of Public Economics 81: 473511. 


\section{Endnotes}

${ }^{1}$ One exception is a study by Schmidt (2008) for the United States. The findings of that study are rather mixed, showing a significant influence of risk attitude only for teenagers but not for adults. However, Schmidt does not distinguish between out-of-partnership birth and cohabiting birth. Moreover, as mentioned by Schmidt (2008: p. 444) herself, the question on risk tolerance was asked after most women in the underlying sample had made their fertility decisions.

${ }^{2}$ As the share of women with a nonmarital birth is very low among immigrants, women with migration background are excluded from the analysis. The low share of immigrants with a nonmarital birth is likely to reflect the fact that a large proportion of immigrants in Germany are from Muslim countries.

${ }^{3}$ In order to ensure that our key result is not solely driven by very young women, we also performed regressions without women younger than 20. This robustness check confirmed our key finding. Moreover, we included an interaction term of the risk tolerance variable and a dummy variable for women older than 30 to examine if the influence of risk attitude differs between age groups. The interaction term did not emerge with a significant coefficient. Most importantly, the coefficient on risk tolerance remained significantly positive.

${ }^{4}$ Excluding women younger than 20 from the analysis or including an interaction term of risk attitude and age does not change the result. 